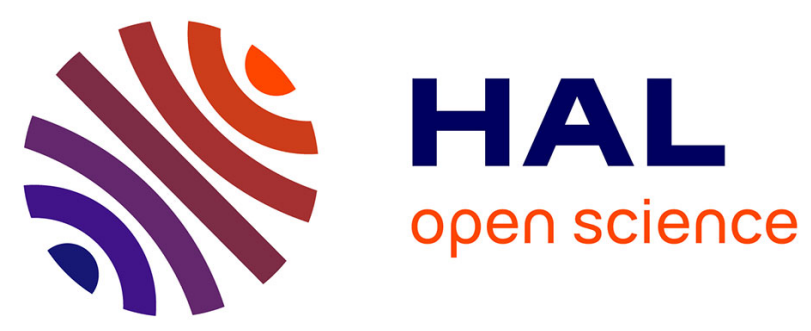

\title{
Phenomenological Constitutive Equations for Numerical Simulations of SMA's Structures. Effects of Thermomechanical Couplings
}

\author{
Robert Peyroux, Andre Chrysochoos, Christian Licht, M. Löbel
}

\section{To cite this version:}

Robert Peyroux, Andre Chrysochoos, Christian Licht, M. Löbel. Phenomenological Constitutive Equations for Numerical Simulations of SMA's Structures. Effects of Thermomechanical Couplings. Journal de Physique IV Proceedings, 1996, 06 (C1), pp.C1-347-C1-356. 10.1051/jp4:1996133 . jpa00254165

\section{HAL Id: jpa-00254165 https://hal.science/jpa-00254165}

Submitted on 1 Jan 1996

HAL is a multi-disciplinary open access archive for the deposit and dissemination of scientific research documents, whether they are published or not. The documents may come from teaching and research institutions in France or abroad, or from public or private research centers.
L'archive ouverte pluridisciplinaire HAL, est destinée au dépôt et à la diffusion de documents scientifiques de niveau recherche, publiés ou non, émanant des établissements d'enseignement et de recherche français ou étrangers, des laboratoires publics ou privés. 


\title{
Phenomenological Constitutive Equations for Numerical Simulations of SMA's Structures. Effects of Thermomechanical Couplings
}

\author{
R. Peyroux, A. Chrysochoos, C. Licht and M. Löbel \\ LMGC - URA 1214, Université Montpellier II, Case 081, Place Eugène Bataillon, 34095 Montpellier \\ cedex 05, France
}

\begin{abstract}
Tension-compression tests at different room temperatures and at different strain rates have been performed on Shape Memory Alloys (CuZnAl, NiTi) using a thermomechanical device. The experiments underline the main role of the temperature variations induced by the deformation process on the stress-strain curves. These variations are essentially due to the latent heat of phase change and the analysis of the associated energy balances shows that the intrinsic dissipated energy remains very small compared to deformation work or latent heat of phase change. On the basis of these results, a behavioral model is proposed that assumes an intrinsic dissipation identically equal to zero and that considers anisothermal deformation processes. This model, written under the formalism of Generalized Standard Materials takes into account the thermoelastic couplings and considers two self-accommodating martensite variants. It is implemented in a finite element code realized to predict the effects of thermomechanical couplings. An implicit integration scheme is used to derive at each step in time the fields stress, strain, temperature, and volume proportions of phases. At each step and due to the thermomechanical coupling, we have to solve nonsymmetric linear systems. Numerical simulations are shown first to verify the coherence with the experimental results obtained under uniaxial loading, and secondly to underline the practical interest of such an approach to design SMA's structures.
\end{abstract}

\section{INTRODUCTION}

Tension-compression tests at different room temperatures and at different strain rates have been performed on Shape Memory Alloys like CuZnAl and NiTi. These experiments, carried out with a thermomechanical device, underline the main role of the temperature variations induced by the deformation process. These variations are essentially due to the latent heat of phase change. The detailed analysis of the associated energy balances shows that the intrinsic dissipated energy remains very small compared to deformation work or latent heat of phase change. On the basis of these results, a behavioral model is proposed that assumes an intrinsic dissipation identically equal to zero and that considers anisothermal deformation processes. This model, written under the formalism of Generalized Standard Materials takes into account the thermoelastic couplings and considers two self-accommodating martensite variants. It is implemented in a finite element code realized to predict the effects of thermomechanical couplings [1]. An implicit integration scheme is used to derive at each step in time the fields stress, strain, temperature, and volume proportions of phases. Numerical simulations are shown first to verify the coherence with the experimental results obtained under uniaxial loading, and secondly to underline the practical interest of such an approach to design SMA's structures. 


\section{THERMODYNAMICAL FRAMEWORK AND EXPERIMENTAL RESULTS}

\subsection{Thermodynamical framework - Energy balance}

To characterize the thermodynamical state of the considered system, the following variables are chosen: $\mathrm{T}$ absolute temperature (we will also use the temperature variation $\theta=\mathrm{T}-\mathrm{T}_{0}$, with $\mathrm{T}_{0}$ the equilibrium absolute temperature), $\varepsilon$ strain tensor (small perturbation hypothesis), $x_{1}$ and $x_{2}$ volume proportions of martensite variants, linked to the phase change strain tensors $\beta^{1}$ and $\beta^{2}$. (The portion of strain due to the phase change is : $\varepsilon^{p c}$ $=x$. $)$.

- Without any heat volume exchange with the outside, the first two principles of thermodynamics can be written as : [2] :

$$
\rho \dot{U}=\sigma: \dot{\varepsilon}-\operatorname{div} q \quad \text { (1) } \quad \text { and } \quad \rho T \dot{s}=D_{1}-\operatorname{div} q
$$

$U$ stands for the total energy of the system,

$\sigma$ is the stress tensor, $q$ the heat influx vector through the outer surface,

$s$ the specific entropy, $\rho$ the volume mass, $D_{1}$ la dissipation intrinsic.

- For a test realizing a thermodynamical cycle (strain, stress and temperature go back to their initial values), the integration along the cycle $C$ of equation (1) gives :

$$
\int_{C} \sigma: \dot{\varepsilon} \mathrm{d} \tau=\int_{\mathrm{C}} \operatorname{div} q \mathrm{~d} \tau=\mathrm{A}_{\mathrm{h}}
$$

noting $\mathrm{U}$ is a state function. $A_{\mathrm{h}}$ stands for the hysteresis area in a $(\sigma, \varepsilon)$ diagram.

Furthermore, using the chosen set of variables $\left(T, \varepsilon, x_{v}\right.$ ) and the classical two definitions of $C_{\alpha}$ (specific heat capacity) and of $\psi(\psi=U-T s)$, Helmholtz free energy) :

$$
\mathrm{C}_{\alpha}=\mathrm{T} \frac{\partial \mathrm{s}}{\partial \mathrm{T}} \quad \text { et } \quad \mathrm{s}=-\frac{\partial \psi}{\partial \mathrm{T}}
$$

we obtain :

$\dot{\mathrm{s}}=\mathrm{C}_{\alpha} \frac{\dot{\mathrm{T}}}{\mathrm{T}}+\frac{\partial \mathrm{s}}{\partial \varepsilon}: \dot{\varepsilon}+\frac{\partial \mathrm{s}}{\partial \mathrm{x}} \quad$ (4), $\rho \mathrm{T} \dot{\mathrm{s}}=\rho \mathrm{C}_{\alpha} \dot{\mathrm{T}}+\rho \mathrm{T} \frac{\partial \mathrm{s}}{\partial \varepsilon}: \dot{\varepsilon}+\rho \mathrm{T} \frac{\partial \mathrm{s}}{\partial \mathrm{x}} \dot{\mathrm{x}}$

(4) and (4') integrated along the cycle $C$ lead to:

$$
\int_{\mathrm{C}} \mathrm{T} \dot{\mathrm{s}} \mathrm{d} \tau=\int_{\mathrm{C}} \rho \theta \frac{\partial \mathrm{s}}{\partial \varepsilon}: \dot{\varepsilon} \mathrm{d} \tau+\int_{\mathrm{C}} \rho \theta \frac{\partial \mathrm{s}}{\partial \mathrm{x}} \dot{\mathrm{x}} \mathrm{d} \tau
$$

When integrating (2) along the same cycle $\mathrm{C}$, (3) we get :

$$
A_{h}=\int_{C} D_{1} d \tau+\int_{C} \rho \theta \frac{\partial^{2} \psi}{\partial T \partial \varepsilon}: \dot{\varepsilon} d \tau+\int_{C} \rho \theta \frac{\partial^{2} \psi}{\partial T \partial x} \dot{x} d \tau
$$

Equation (5) allows to decompose the hysteresis area in a part resulting from the intrinsic dissipation $\mathrm{D}_{1}$, a part resulting from the thermoelastic couplings, called isentropic coupling, and a part resulting from phase change effects. 
- We find again these different terms in the expression of heat equation, written here assuming a Fourier conduction law $(\mathrm{q}=-\lambda \cdot \operatorname{grad}(\mathrm{T}))$ where $\lambda$ is the thermal conduction tensor, assumed to be constant:

$$
\rho \mathrm{C}_{\alpha} \dot{\theta}-\lambda . \Delta \theta=\mathrm{D}_{1}+\rho \mathrm{T} \frac{\partial^{2} \psi}{\partial \mathrm{T} \partial \varepsilon}: \dot{\varepsilon}+\rho \mathrm{T} \frac{\partial^{2} \psi}{\partial \mathrm{T} \partial \mathrm{x}} \dot{\mathrm{x}}=\mathrm{w}_{\mathrm{ch}}^{\prime}
$$

$\mathrm{w}_{\mathrm{ch}}$, right hand side of the equation, is the volume heat source, that can be computed by evaluating the left hand side of (6) thanks to temperature measurements [3].

Connecting (4) and (5), we deduce, for any thermodynamical cycle :

$$
A_{h}=\int_{C} w_{c h}^{\prime} d \tau
$$

In order to quantify the importance of the dissipation terms and of the thermomechanical coupling terms, one can introduce [4] the coefficient $R_{\mathrm{T}}$ defined by :

$$
0 \leq \mathrm{R}_{\mathrm{T}}=\frac{\mathrm{A}_{\mathrm{h}}}{\overline{\mathrm{A}_{\mathrm{h}}}} \leq 1 \quad \text { with } \quad \overline{\mathrm{A}_{\mathrm{h}}}=\int_{\mathrm{C}}\left|\mathrm{w}_{\mathrm{ch}}\right| \mathrm{d} \tau
$$

Just remember that intrinsic dissipation is always positive and that coupling terms change sign at every change of loading. Due to this, and for tension-compression loadings, the more the dissipation is preponderant, the closer $R_{T}$ is to 1 . Conversely, the closer $R_{T}$ is to 0 , the more the dissipation can be energetically negligible compared with the heat evolved by thermomechanical couplings.

\subsection{Analysis of experimental results [5] and [6]}

The related tests have been performed on $\mathrm{CuZnAl}$ and $\mathrm{NiTi}$ alloys. The experimental device allows uniaxial tension compression loadings at different strain rates and with a controlled room temperature (with an environment chamber). Several loading paths in a stress temperature plane were prescribed, and the amounts of heat involved during the tests were deduced from the temperature measurement made by thermocouples or by infrared thermography. the main results are :

- The analysis of mechanical and thermal measurements points out a transition domain delimited by half lines (fig. 1), pointing to the beginnings and the ends of austenite - martensite transformation. The width of this domain can be characterized by the difference between temperatures $\mathrm{A}$ and $\mathrm{M}$, (respectively beginning and end of austenite - martensite transformation under zero stress).

- The experiments realized at different room temperature show (fig. 2) different mechanical responses. Furthermore, the amplitude of temperature variations due to the austenite - martensite transformation is not negligible in comparison with (A-M) (Fig. 3b). These two facts attest the importance of taking into account the temperature in the analysis of shape memory alloys behavior.

- The experiments realizing thermodynamical cycles (zero values of strain and stress at the end of experiment, and same temperature, after a while, than initial reference temperature), have all shown values of ratio $\mathrm{R}_{\mathrm{T}}$ (equation 8 ) less than 0.02 , proving the weak value of dissipated energy along a cycle in comparison with the global heat evolved by thermomechanical couplings. 
- The amounts of energy $W_{c h}$ (corresponding to the evolved heat) and $W_{m}$ (deformation work) are given by :

$$
\mathrm{W}_{\mathrm{ch}}=\mathrm{V}_{0} \int_{\mathrm{t}_{\mathrm{ini}}}^{\mathrm{t}} \mathrm{w}_{\mathrm{ch}}^{\prime} \mathrm{d} \tau \text { and } \quad \mathrm{W}_{\mathrm{m}}=\mathrm{V}_{0} \int_{\mathrm{t}_{\text {ini }}}^{\mathrm{t}} \sigma: \dot{\varepsilon} \mathrm{d} \tau
$$

Their evolution during the test (fig. 3a) show the importance of the latent heat associated to phase change in comparison with $\mathrm{W}_{\mathrm{m}}$. The ratio $\mathrm{W}_{\mathrm{ch}}$ to $\mathrm{W}_{\mathrm{m}}$ is about 10 for $\mathrm{CuZnAl}$ and 3 for NiTi.

- Finally, calling $W_{\text {is }}$ the energy term du to thermomechanical couplings (see equation (5)), we define $W_{L}$ as the difference between $\mathrm{W}_{\mathrm{ch}}$ and $\mathrm{W}_{\mathrm{is}}$. Then, keeping the hypothesis of a weak dissipation in comparison with the others energetic terms, $W_{L}$ stands for the amounts of energy associated to phase change. On fig.4 we can see that $\mathrm{W}_{\mathrm{L}}$ is proportional to $\varepsilon^{\mathrm{pc}}$ (portion of strain due to phase change). This result has been confirmed for all the thermomechanical loadings used and allows to characterize the relationship between energy used in the phase change and the volume proportion of transformed material.

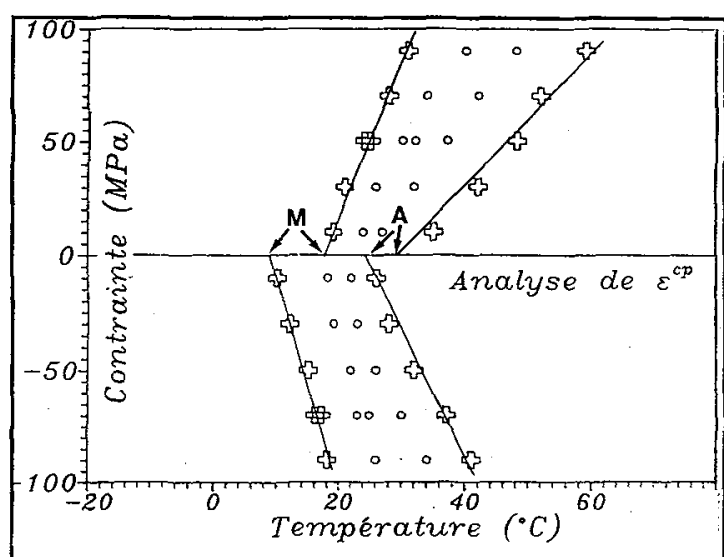

Figure 1 : Transition domains observed for a CuZnAl alloy

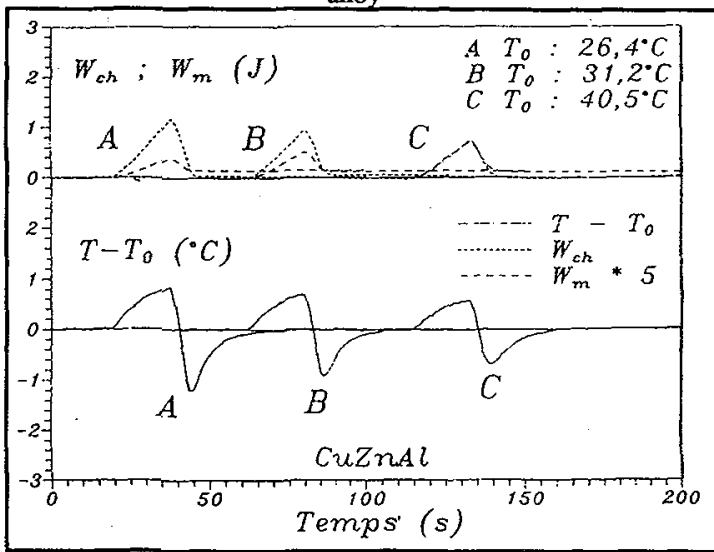

Figure 3 : Evolution during the test of the sample temperature (3a) and of quantities $W_{c h}$ and $W_{m}(3 b)$, for 3 values of imposed room temperature

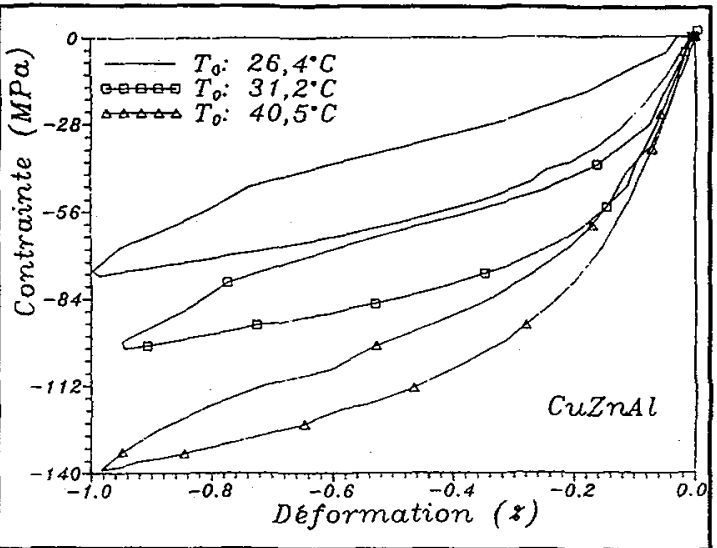

Figure 2 : Stress-strain curves for a compression test, for 3 values of imposed room temperature.

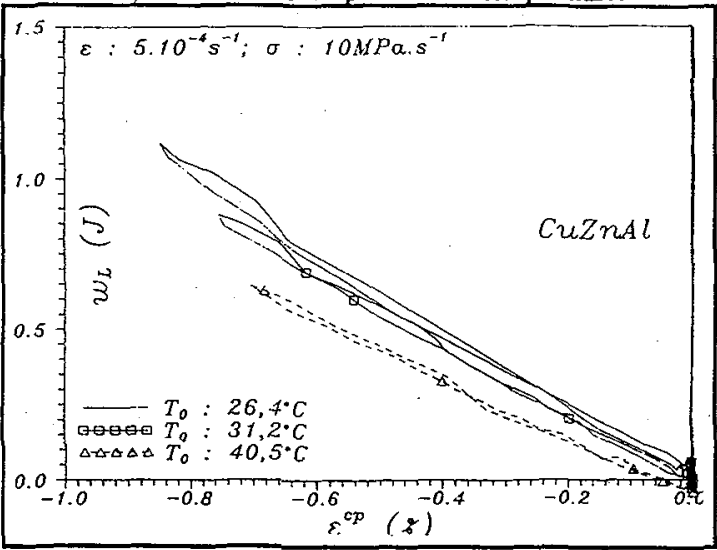

Figure 4 : Relationship between $W_{L}$, phase change energy and $\varepsilon^{\mathrm{pc}}$, portion of strain due to phase change 


\section{DERIVATION OF THE MODEL - BEHAVIOR LAWS}

We suggest a behavioral model for these materials that takes into account of the preceding experimental results, and we choose the thermodynamical framework of Generalized Standard Materials. Classically, Two potentials are introduced, $\psi$ free energy potential, D dissipation potential, as functions of the state variables and their derivatives with respect to time. The state laws and the complementary laws are then deduced from these potentials.

\subsection{Free energy potential - State laws}

The set of state variables used to describe the behavior is : $\left(\varepsilon, T, x_{V}\right)$.

The considered behavior is a coupled thermoelastic one, taking into account the effects of phase change.

- The free energy $\psi$ is decomposed into $\psi_{\mathrm{e}}$ (corresponding to thermoelastic effects) and $\psi_{\mathrm{ch}}$ (corresponding to phase change effects),

$\rho \psi_{\mathrm{e}}=\frac{1}{2}\left[\mathrm{a}_{\mathrm{ijkl}}\left(\varepsilon_{\mathrm{kl}}-\alpha_{\mathrm{kl}} \theta-\mathrm{x}_{\mathrm{v}} \beta_{\mathrm{kl}}^{\mathrm{v}}\right)\left(\varepsilon_{\mathrm{ij}}-\alpha_{\mathrm{ij}} \theta-\mathrm{x}_{\mathrm{v}} \beta_{\mathrm{ij}}^{\mathrm{v}}\right)-\left(\mathrm{C}+\mathrm{a}_{\mathrm{ijkl}} \alpha_{\mathrm{kl} l} \alpha_{\mathrm{ij}}\right) \theta^{2}\right]$

(In this expression, suffix $v$ in the product $x \beta$ must be summed over 1 and 2 )

$$
\rho \psi_{c h}=D\left[(A-M)\left(x_{1}^{2}+x_{2}^{2}\right)+(T-A)\left(x_{1}+x_{2}\right)\right]
$$

- Finally, as $\mathrm{x}_{1}$ are $\mathrm{x}_{2}$ are volume fractions they must stay in the set $\mathrm{V}$ defined by :

$$
V=\left\{\left(x_{1}, x_{2}\right) \in R^{2} / 0 \leq x_{v} \leq 1, v=1,2 \text { et } 0 \leq x_{1}+x_{2} \leq 1\right\}
$$

$\mathrm{V}$ is then a triangle in the plane $\left(\mathrm{x}_{1}, \mathrm{x}_{2}\right)$ (see figure below).

To take account of these inequalities, one can introduce, in the expression of free energy, [7] and [8], the indicator function of $\mathrm{V}, \mathrm{I}_{\mathrm{V}}$, defined by :

$$
\operatorname{IV}\left(\mathrm{x}_{1}, \mathrm{x}_{2}\right)=\left\{\begin{array}{l}
0 \text { if }\left(x_{1}, x_{2}\right) \in V \\
+\infty \text { if not }
\end{array}\right.
$$

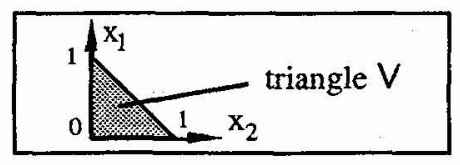

We will finally keep the following expression of $\psi$ :

$$
\rho \psi=\rho \psi_{e}+\rho \psi_{c h}+I_{v}\left(x_{1}, x_{2}\right)
$$

and consequently we impose an infinite value to $\psi$ when the values of $x_{1}$ and $x_{2}$ are not physically admissible. 
- The derivation of the partial derivatives of $\psi$ with respect to $\varepsilon$ an to $\mathrm{T}$ gives :

$$
\begin{aligned}
& \rho \frac{\partial \psi}{\partial \varepsilon_{\mathrm{ij}}}=\sigma_{\mathrm{ij}}=\mathrm{a}_{\mathrm{ijkl}}\left(\varepsilon_{\mathrm{kl}}-\alpha_{\mathrm{k} 1} \theta-\mathrm{x}_{\mathrm{v}} \beta_{\mathrm{kl}}^{\mathrm{v}}\right) \quad \text { stress tensor } \\
& \mathrm{C}_{\alpha}=\mathrm{T} \frac{\partial \mathrm{s}}{\partial \mathrm{T}}=-\mathrm{T} \frac{\partial^{2} \psi}{\partial \mathrm{T}^{2}}=-\mathrm{T} \mathrm{C} \text { specific heat capacity }
\end{aligned}
$$

\subsection{Dissipation potential - Complementary laws}

- In order to translate the experimentally undetected intrinsic dissipation, the mechanical dissipation potential is chosen identically equal to zero. This implicates that the thermodynamical force $\mathrm{X}^{\mathrm{v}}$ associated to $\mathrm{x}_{\mathrm{v}}$ is identically equal to zero.

Calling $X^{\mathrm{v}}$ the regular part of $\mathrm{X}^{\mathrm{v}}$ that is :

$X^{v}=\frac{\partial \psi_{\mathrm{e}}}{\partial \mathrm{x}_{\mathrm{v}}}+\frac{\partial \psi_{\mathrm{ch}}}{\partial \mathrm{x}_{\mathrm{v}}}$, we derive : $X^{I} \in \partial_{1} \mathrm{I}_{\mathrm{V}}\left(\mathrm{x}_{1}, \mathrm{x}_{2}\right)$ et $X^{2} \in \partial_{2} \mathrm{I}_{\mathrm{V}}\left(\mathrm{x}_{1}, \mathrm{x}_{2}\right)$

where $\partial_{v} I_{V}\left(x_{1}, x_{2}\right)$ stands for the components of the sub-differential with respect to $x_{v}$ of the indicator function $I_{V}$. The point is, using these two relations, to write some conditions on the vector $\vec{X}=\left(X^{1}, X^{2}\right)$ when the vector $\vec{x}=\left(x_{1}, x_{2}\right)$ describes triangle $\mathrm{V}$.

If the point is inside triangle $V$, then $\vec{X}=\overrightarrow{0}$, if $\vec{x}$ is on the boundary of $\mathrm{V}$, then $\vec{X}$ belongs to the normal cone to $\mathrm{V}$.

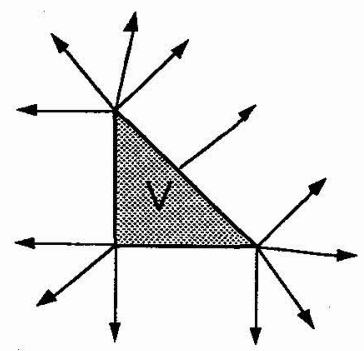

The advantage of this mathematical formalism consists in his ability to describe correctly the non regular points of domain $V$ (for $\vec{x}=\overrightarrow{0}, \vec{x}=(1,0), \vec{x}=(0,1)$ ). Furthermore, and in light of expressions (9-1), (9-2) and (9-3), equation (14) becomes :

$\left.\begin{array}{l}\left.-\sigma_{i j}: \beta_{i j}^{1}+D_{[} 2(A-M) x_{1}+(T-A)\right] \in \partial_{1} I_{V}\left(x_{1}, x_{2}\right) \\ -\sigma_{i j}: \beta_{i j}^{2}+D_{\left[2(A-M) x_{2}+(T-A)_{]}\right.} \in \partial_{2} I_{V}\left(x_{1}, x_{2}\right)\end{array}\right\}$

In the following, $Z$ will stand for the quantity $\frac{\sigma_{\mathrm{ij}} \beta_{\mathrm{ij}}}{\mathrm{D}}$, that qualify the importance of stress level.

- The investigation of the possible situations of $\vec{x}$ in V and the derivation of the corresponding values of $\vec{X}$ allow to define, in a $(\mathrm{Z}, \mathrm{T})$ plane, the different transition domains between austenite and the two martensite variants (fig. 5). Concerning temperature higher than $A$ and low values of $\mathrm{Z}$, only austenite is present. For temperature lower than $M$, there is no more austenite, and if $|Z|<A-M$, Both martensite variants exist. Between $M$ and $A$, and for $|Z|<A-M$, there is a zone where the three phases are present.

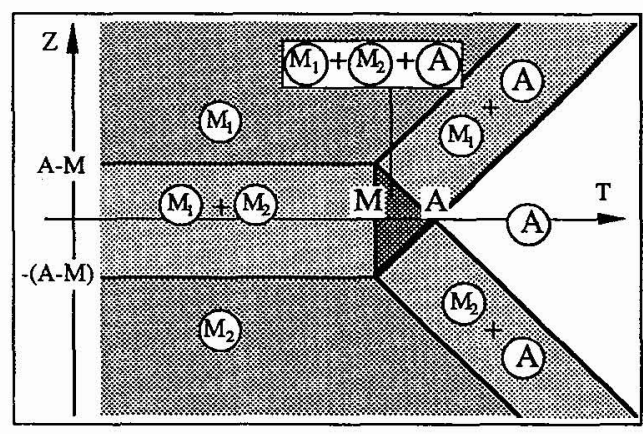

Figure 5 : Transition domains in the $(Z, T)$ plane 


\subsection{Heat equation}

- In order to work under the hypothesis of a dissipation identically equal to zero, the heat equation (6) becomes :

$$
\frac{\rho \mathrm{C}_{\alpha}}{\mathrm{T}_{0}} \dot{\theta}-\frac{\lambda}{\mathrm{T}_{0}} \cdot \Delta \theta=-\mathrm{a} \alpha: \dot{\varepsilon}+\frac{\rho \mathrm{L}^{\mathrm{v}}}{\mathrm{T}_{0}} \dot{\mathrm{x}}_{\mathrm{v}}
$$

where $L^{v}=\frac{T_{0}}{\rho}\left(a \alpha: \beta^{v}+D\right)$ is the phase change latent heat of the variant $v$.

\subsection{The final behavior laws}

In a first step, in order to perform basic numerical simulations of SMA behavior, we made the following assumptions :

- The thermoelastic behavior is supposed to be isotropic. Hence, the material will be describe by its Young's modulus E and its Poisson's ratio $v$, and by a thermal dilatation coefficient $\alpha$.

- The phase change strain tensors $\beta^{1}$ et $\beta^{2}$ are supposed to satisfy :

$$
\operatorname{Tr}\left(\beta^{\mathrm{v}}\right)=0 \quad \text { et } \quad \beta_{\mathrm{ij}}^{1}+\beta_{\mathrm{ij}}^{2}=0,
$$

in order to translate iso-volumic strain and auto-accommodation properties for the two variants.

Let $\beta=\beta^{1}=-\beta^{2}$.

- These two assumptions allow to write the latent heat as: $L=\frac{T_{0}}{\rho} D$

- Consequently, the final behavior laws are :

$$
\begin{aligned}
& \sigma_{\mathrm{ij}}=\mathrm{a}_{\mathrm{ijk} l}\left(\varepsilon_{\mathrm{kl}}-\alpha_{\mathrm{k} l} \theta-\left(\mathrm{x}_{1}-\mathrm{x}_{2}\right) \beta_{\mathrm{kl}}\right) \\
& \frac{\rho \mathrm{C}_{\alpha}}{\mathrm{T}_{0}} \dot{\theta}-\frac{\lambda}{\mathrm{T}_{0}} \Delta \theta=-\mathrm{a}_{\mathrm{ijkl}} \alpha_{\mathrm{kl}}: \dot{\varepsilon}_{\mathrm{ij}}+\frac{\rho \mathrm{L}}{\mathrm{T}_{0}}\left(\dot{\mathrm{x}}_{1}+\dot{\mathrm{x}}_{2}\right)
\end{aligned}
$$

Combined with expressions (15) we can link the stress field, the temperature and the volume proportions of martensite.

\section{NUMERICAL SIMULATIONS}

\subsection{The numerical method}

The numerical method relies upon a finite element spatial discretisation (3 nodes triangles with linear interpolation functions). For a two-dimensional solution, each node on the mesh owns three degrees of freedom, two for displacements and one for temperature. 
Time discretisation uses an implicit schema allowing, at each step in time, to derive the fields of stress $(\sigma)$, displacement $(u)$, temperature $(\theta)$ and volume proportions $\left(\mathrm{x}_{\mathrm{v}}^{\mathrm{k}}\right)$ of transformed phase.

The step in time $\mathrm{k}$ begins with given fields $\sigma^{\mathrm{k}}, \mathrm{u}^{\mathrm{k}}, \theta^{\mathrm{k}}$ et $\mathrm{x}_{\mathrm{v}}^{\mathrm{k}}$. The discretised problem reduces to a linear system solution giving $\mathrm{u}^{\mathrm{k}^{\prime}}$ et $\theta^{\mathrm{k}^{\prime}}$, in terms of $\mathrm{u}^{\mathrm{k}}, \theta^{\mathrm{k}}, \mathrm{x}_{\mathrm{v}}^{\mathrm{k}}$ and the loading conditions. We then derive $\mathrm{x}_{\mathrm{v}}^{\mathrm{k}^{\prime}}$ as a function of $\theta^{\mathrm{k}^{\prime}}$ and $\sigma^{\mathrm{k}^{\prime}}, \sigma^{\mathrm{k}^{\prime}}$ being evaluated from $\mathrm{u}^{\mathrm{k}^{\prime}}, \theta^{\mathrm{k}^{\prime}}$ et $x_{\mathrm{v}}^{\mathrm{k}}$ and iterate the problem solution and the computation of $x_{v}^{k^{\prime}}$ up to the process convergence (convergence is estimated from the successive values of $x_{v}^{k^{\prime}}$ ). At this time, the computed values are $\sigma^{k+1}, u^{k+1}, \theta^{k+1}$ and $x_{v}^{k+1}$, and step in time $k+1$ can begin.

Another difficulty to reduce is that the computed system is, at each step in time and at each iterative path, a non symmetric one. This is du to the isentropic coupling term in the heat equation and requires a systematic use of skyline storage.

Finally, the boundary conditions available are imposed displacements and temperature, given effort or heat influx, and also mixed boundary conditions on the surface (like $X_{h}\left(T-T_{e x t}\right)$ where $T-T_{\text {ext }}$ represents the difference between the surface temperature and a prescribed room temperature, and where $X_{h}$ is an exchange coefficient.)

\subsection{The numerical simulations}

We simulated the behavior of a shape memory alloy such as CuZnAl with the following set of coefficients.

Young's modulus $\mathrm{E}=8.5 \mathrm{E} 10 \mathrm{Mpa}$

Poisson's ratio $\mathrm{v}=0.3$

Thermal dilatation coefficient $\alpha=1.7 \mathrm{E}-05^{\circ} \mathrm{C}^{-1}$

Thermal Conductivity $\lambda=120 \mathrm{~W} / \mathrm{m}^{\circ} \mathrm{C}$

Specific heat capacity $\mathrm{C}_{\alpha}=390 \mathrm{~J} / \mathrm{kg}^{\circ} \mathrm{C}$

Volume mass $\rho=7900 \mathrm{~kg} / \mathrm{m}^{3}$

Latent heat $\mathrm{L}=7000 \mathrm{~J} / \mathrm{kg}$

Phase change strain tensor $\beta$ : $\beta_{11}=6 \mathrm{E}-02, \beta_{22}=-6 \mathrm{E}-02, \beta_{33}=0$, other $\beta_{\mathrm{ij}}$ equal zero.

Reference temperature $\mathrm{T}_{0}=20^{\circ} \mathrm{C}$.

Temperature associated to the beginning and the end of transformation, $M=5^{\circ} \mathrm{C}$ et $\mathrm{A}=20^{\circ} \mathrm{C}$

- The aim of the first numerical tests was to verify the consistency with the experimental experiments. The studied structure (here a sample) is a rectangular piece of $10 \mathrm{~cm}^{2}$, the corresponding mesh contains 121 nodes and 200 elements and the prescribed loadings consist in imposed displacements on one side, simulating a tension-compression test along axis 1.

Relating to the test presented below, the imposed displacement (time proportional) allows to reach tension and compression strains up to $2 \%$. The room temperature is kept constant and equals $19^{\circ} \mathrm{C}$. Figure 6 shows the executed path in a $(Z, \theta)$ plane. The broken lines show a portion of the transition domain defined in figure 5. The first loading path (tension 0-2) is done while the sample has not reached yet a thermal 
equilibrium with respect to the room temperature. The portion (0-1) is concerned with low temperature variations (isentropic coupling alone). In (1), we enter martensite variant 1 domain and the latent heat terms induce much more significant temperature variations. In the course of time, a thermal equilibrium is reached around the room temperature $\left(19^{\circ} \mathrm{C}\right.$ or $\left.\theta=-1^{\circ} \mathrm{C}\right)$, and the following loops (3-4) are stabilized. In (2) the value of $\mathrm{x}_{1}$ is about 0.33 .

Figure 7 shows the evolution of stress along the loading axis versus the strain in the same direction. Here again, we observe a stabilization of the hysteresis loops from the second loading (2).

These two figures are plotted for a point of the exterior surface of the sample

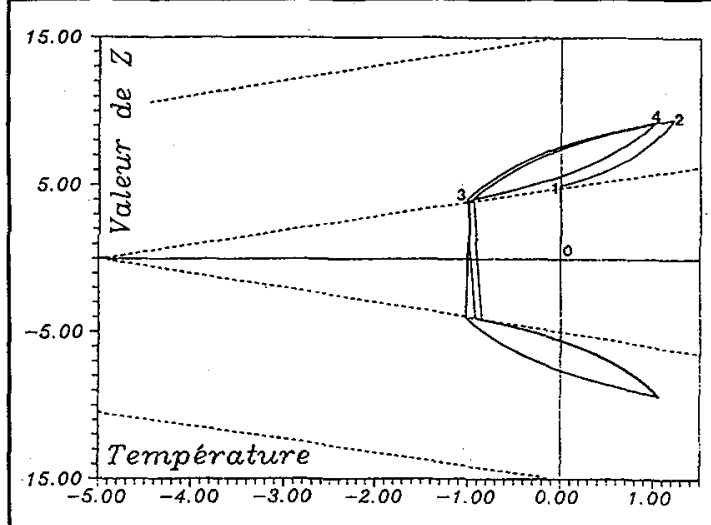

Figure $6:(Z, \theta)$ curve

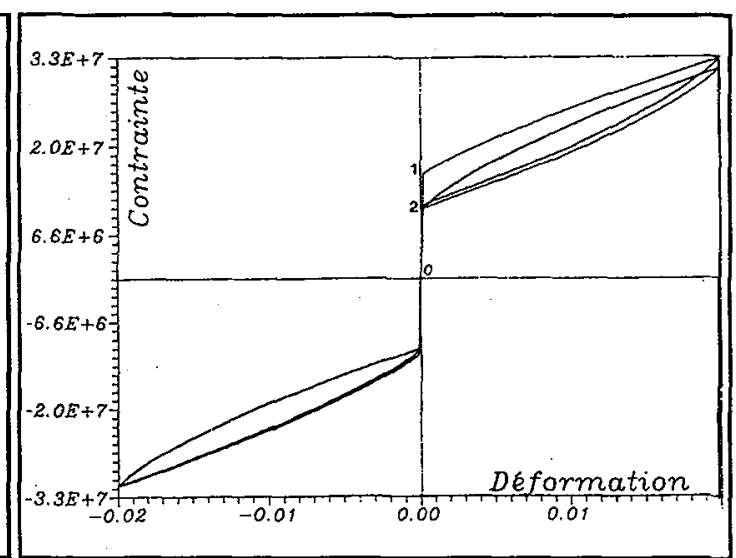

Figure 7 : Stress - strain curve

- It can be of some interest to study the importance of the heterogeneous aspect of the transformation (unavoidable in view of the conditions of heat diffusion). In fact, during these cyclic loadings, the temperature fields can show variations of 3 to 4 degrees between a point in the center of the sample and a point on its boundary. On an other hand, the variations of $x_{k}$ between the same points are less than $1 \%$. Hence, the transformation can be considered as uniform.

- Others numerical tests were performed in order to describe completely the transition domain of figure 5. (In particular simulations allowing an entire crossing of the transition domain, others for variable room temperature and zero stress and finally simulations with variable stress and given room temperature less than $\mathrm{M}$ (autoaccommodation phenomema)).

- Finally, the last tests performed are intended to underline the practical interest of these approaches when designing structures using SMA. (Computation of the efforts in a constrained structure under temperature variations, investigation of the tightening effort in a collar, ...). Giving access to the fields of stress, temperature and volume proportions of transformed phase, the finite element method is found to be totally efficient. 


\section{CONCLUSIONS}

Using a coherent thermodynamical framework, the analysis of experimental results obtained on shape memory alloys allowed us to make some assumptions, especially concerning the anisothermal aspect of the transformation and the weakness of the intrinsic dissipation evolved in comparison with phase change latent heat. These hypothesis are at the source of a behavioral model for these materials that takes into account existing thermomechanical couplings. This model extended with a finite element method, makes it possible to perform numerical simulation of structures or samples made with shape memory alloys. In spite of some simplifications of the behavior (only two martensite variants existing in the model), the obtained results are in good agreement with experimental observations.

Outstanding improvements are related to a much more precise description of the physical aspects of the transformation (increase of the number of potential variants) in order to get a better translation of the material behavior in a structure design. Considering another scale (grains in a polycrystal), an other research line consists in a better characterization of the material behavior especially by taking into account the connections between crystallographic orientations and possible transformation.

\section{REFERENCES}

[1] PEYROUX R., LICHT C. : Homogenization in thermoelasticity : application to composite materials, EUROMAT 93, Paris, june 1993, in Journal de Physique IV, Colloque C7, suppl. au J. de Phys. III,vol. 3, nov. 1993.

[2] GERMAIN P. : Cours de Mécanique des Milieux Continus, Tome 1, Masson, 1973.

[3] CHRYSOCHOOS A., DUPRE J.C. : An infra-red set-up for Continuum Thermomechanics, Actes du Colloque QIRT, juillet 1992, Eurotherm. Seminar 27 Editions Européennes Thermiques et Industries, in press.

[4] PHAM H. : Analyse thermomécanique du comportement d'un alliage à mémoire de forme de type Cu-ZnAl, Thèse de Doctorat, Université Montpellier II, février 1994.

[5] PHAM H. : Analyse thermomécanique du comportement d'un alliage à mémoire de forme de type Cu-Zn$A l$, Thèse de Doctorat, Université Montpellier II, février 1994.

[6] CHRYSOCHOOS A., LÖBEL M., MAISONNEUVE O. : Couplages thermomécaniques du comportement pseudoélastique d'alliages Cu-Zn-Al et Ni-Ti, CRAS, t. 320, série II, à paraitre, 1995.

[7] FREMONT M. : Matériaux à mémoire de forme, CRAS, t. 304, série II, 239-245, 1987.

[8] LEXCELLENT C., LICHT C. : Some remarks on the modelling of the thermomechanical behaviour of shape memory alloys, J. de Ph. Appl., 4, C4, vol. n¹, Nov., pp. 35-39, 1991. 